\title{
A Social Framework for Supporting, Evaluating and Validating Informal Learning
}

\author{
Nikolas Galanis, Enric Mayol, Marc Alier \\ Universidad Politécnica de Catalunya - BarcelonaTech \\ UPC Campus Nord, Omega S206 \\ Jordi Girona 1-3, 08034, Barcelona, Spain \\ (+34) 934137174 \\ \{ngalanis, mayol, ludo\}@essi.upc.edu
}

\author{
Francisco José Garcia-Peñalvo \\ Universidad de Salamanca \\ Plaza de los Caídos s/n \\ 37008, Salamanca, Spain \\ (+34) 923294500 \\ fgarcia@usal.es
}

\begin{abstract}
Validation of informal learning has been a hot topic in the European Union the past few years. A number of guidelines and proposals have been published providing competence catalogues for direct transition from informal to formal learning. In our work, we propose the usage of a more social and dynamic framework for validating and promoting a learner's informal learning.
\end{abstract}

\section{Categories and Subject Descriptors}

K.3.1 [Computers and Education]: Computer Uses in Education - Collaborative learning, Computer-assisted instruction (CAI)

K.3.2 [Computers and Education]: Computer and Information Science Education - Accreditation, Curriculum

\section{General Terms}

Algorithms, Measurement, Human Factors, Standardization.

\section{Keywords}

Informal learning, non-formal learning, e-learning, eLearning, lifelong learning, social, validation, evaluation.

\section{INTRODUCTION}

The unprecedented growth of the Internet has defined modern life more than any other recent technological advance. Thanks to the Internet, we enjoy access to global connectivity and all the information that comes as a result. The versatile nature of the Internet has proven to be the ideal conductor for all kinds of information exchange. It provides a dynamic framework that allows for all kinds of communication, whether unidirectional or bidirectional, synchronous or asynchronous, symmetric or asymmetric. The benefits of having this wealth of knowledge at our fingertips are not easily quantifiable. Most times, access to knowledge is just a few keystrokes and mouse clicks away, whether provided by specialized digital knowledge platforms or by custom Internet searches. The simple act of aimlessly navigating the Internet can provide an important amount of information. All this information inevitably leads to knowledge, and given the amount of information we are exposed to constantly, this knowledge begins to gain important dimensions that cannot and should not be neglected when examining the competences of individuals.

The wealth of information we have access to, has brought forth the emergence of what is called the modern Knowledge Society $[1,2]$. Knowledge has always been one of the primary motivators of human progress. The search for answers and the effort put into understanding out surroundings is responsible for the non-stop evolution of our species. We are living in a time when we are enjoying more access to knowledge than ever before. Whether in terms of quality, quantity, general availability and ease of access, knowledge is more present than ever in our everyday life and there is little doubt that the main facilitator for the emergence of this modern knowledge society is the Internet.

The learning potential offered by the Internet to anyone who has access to it regardless of age and social or financial background, has led to a rising interest in the concept of lifelong learning. A number of organizations, foundations and projects like the University of the Third Age (U3A) [3] and the Lifelong Learning Programme of the European Community [4], are centered in promoting and facilitating continuous learning for all kinds of social, ethnic and economic groups.

Inherent to lifelong learning are the concepts of formal, informal and non-formal learning. Formal learning refers to the education received from a recognized education center that leads to a certification, with everything else being either non-formal or informal learning. An example of non-formal learning would be taking swimming lessons at the pool, while watching a tutorial video on how to change a car tire would be informal learning.

Since 2004, the European Council has recognized the importance of non-formal and informal learning and has been taking steps to define a set of guidelines for their validation [5]. The goal of the European Council is to quantify which skills are available in the European workforce in an effort to promote better matching between the demand and the availability of skills within Europe.

The active role of Information and Communication Technologies (ICTs) in almost all lifelong learning initiatives is very well documented. Punie et al. [6] present a collection of evidence that modern education is heavily impacted by ICTs and come to the conclusion [7] that non-formal, informal and adult learning are becoming important for the future of learning.

An important thing to note at this point is that the lines between formal, non-formal and informal education are becoming blurred in the sense that we end up participating in more than one of these types of learning at the same time. For this reason it is important to take into account the effort put into learning outside the formal structures and evaluate individuals accordingly. It would be an error to continue evaluating individuals solely based on their formally attained degrees when we are exposed daily to so much 
information that we are essentially constantly taking part in informal learning activities.

This raises the following question: Can the knowledge obtained through non-formal and informal means be quantified and evaluated in order to be formalized and recognized within the competences of a curriculum?

An attempt towards tackling this question was carried out by the TRAILER (Tagging, Recognition and Acknowledgement of Informal Learning Experiences) project $[8,9,10]$. The goal of the TRAILER project was to provide a methodology and a software platform that would facilitate communication of informal learning experiences between learners, employees and businesses. Our experiences during the lifetime of TRAILER led to our decision to continue working on the representation and evaluation of informal learning.

Even though describing informal learning activities is a relatively simple process, it is much more complex to define a complete model that describes the knowledge we acquire with these activities. Concretely, the main difficulty inherent to the informal learning process is the validation and evaluation of the acquisition of this informal knowledge.

In this work, we aim to propose an approach towards validating informal learning that is not based upon an unwieldy list of competences or solely upon a strict rule set. We are proposing a social-oriented framework that on top of a set of rules and predefined competences, uses social engineering and peer interaction to not only validate, but to also promote informal learning. To the best of our knowledge, there are no other works in the literature that take this approach.

The rest of this paper is organized as follows: Section 2 presents a review of the state of the art centered on EU initiatives, tools that aid informal learning and work done on competences. Section 3 presents a list of challenges that concern the informal learning validation process. Section 4 presents our proposal for a social approach to the issue of validation and evaluation. Section 5 analyzes the benefits we view to our approach. Section 6 provides an analysis of the perceived risks to implementing our proposal. Section 7 details our intended evaluation procedure. Finally, in section 8 we present our conclusions.

\section{STATE-OF-THE-ART}

\subsection{European Union Initiatives}

The European Union has been involved in the subject of informal learning for a number of years. The Bologna treaty that was signed in 1999 [11] recognized informal learning as a basic element of lifelong learning. Since then, there have been a number of European initiatives for validating informal and non-formal learning. The European Centre for the Development of Vocational Training (CEDEFOP) [12], gathers experiences of informal learning from the different European countries and tries to define European qualifications through tools like the European Qualifications Framework (EQF) [13] which is a common reference framework that aims to link the qualification systems of the different European countries.

In order to support informal learning, the European Union defined it as an important part of its Lifelong Learning Programme [4]. The program acknowledges that European countries are increasingly aware that an individual's knowledge and qualifications in terms of skills and competences are heavily defined by their informal and non-formal learning activities. For this reason there is an ongoing effort searching for solutions on the problem of validation of such learning experiences. In order to correctly validate them these experiences first need to be identified, documented and assessed. The Inventory project [14] provides a concise list of the situation on validating informal learning in $30 \mathrm{EU}$ countries. From all the documented experience, the authors distinguish eight use-cases that they consider to be good practice. The authors conclude that in general, the EU countries have taken steps towards validating informal learning, but the mechanisms employed by the different countries lack cohesion and coordination, complicating the communication of competences gained through informal learning among the different countries.

CEDEFOP published in 2009 a set of guidelines for validating non-formal and informal learning [5]. This document is presented as a practical tool containing a framework of guidelines to be applied voluntarily. The authors believe that a common framework for validation will serve as a way to promote nonformal and informal learning among the European citizens, since it will benefit them with recognition of their efforts at a European level, instead of just a national one. Validation is considered on four different levels or perspectives: European, national, organizational and personal. All four are considered equally important and should be taken into account throughout the validation process. The authors argue that non-formal and informal learning can be validated using the same standards and benchmarks as formal learning. According to them, this is also a good way to increase the legitimacy of informal learning. Broad acceptance of the validation methodology is essential for it to have any chance of success.

\subsection{Informal Learning Tools}

The recognized importance of informal learning has inevitably led to the development of a number of tools that aim to aid and promote the concept and assist the learners with their activities.

Some of these tools are designed as platforms for promoting and facilitating informal learning. Examples of such platforms are FREE (Fostering Return to Employment through Entrepreneurship, Innovation and Creativity) [17] and IBAK [18]. FREE is an interactive tool aimed towards people working with the unemployed. Its aim is to help these people improve their hard and soft skills so that they may provide a better service to the unemployed. Similarly, IBAK is an EU funded project addressed to professionals working in the field of lifelong learning and aims to help adult education institution by providing a framework for identifying, assessing and recognizing informally acquired competences.

Apart from platforms providing assistance to those that work in adult and lifelong learning, there are those that aim at recording and identifying the competences an individual has acquired through informal learning. These tools are usually portfolios or similar software like TENCompetence [19, 20], Mahara [21, 22, 23], Mozilla's OpenBadges [24] and Degreed [25]. ePortfolios are regarded among the ideal tools for lifelong learning [26].

Mahara is an ePortfolio software in the traditional sense of the term. Users can gather all their titles, degrees or competences whether obtained through formal means or not. Such a platform can help users give visibility to their informal learning activities by presenting them alongside their formal learning and in an equal format. However, there is always a risk of not being able to adequately represent competences acquired through informal means precisely due to the potential lack of structure of such 
activities. Such a case would be a portfolio that requires a rigid structure when defining activities and competences.

TENCompetence is a European open source project aiming to provide an infrastructure [27] that fosters lifelong learning. TENCompetence is more focused on the competences an individual obtains throughout their life. For this reason, it provides tools for creating a competence profile. To serve as a desktop tool for the project, the TENCompetence ePortfolio was proposed in order to provide the learners with a tool they could use to organize their competence profile. The Personal Competence Manager [28] was developed as a result.

OpenBadges and Degreed are trying to provide some more tangible reward to a learner's informal learning activities in the form of badges or scores respectively. This provides an additional incentive for the learners to register their activities since they are getting an immediate reward. Despite this reward being more psychological than actually important, it has been proven to work very well as a way to keep users coming back and try to earn more of the available awards. Keeping an inventory of activities can be a tedious undertaking in itself, and any small reward for doing it can make a lot of difference. Moreover, the ability to be able to compare these rewards to those of your contacts creates a healthy competition that further fosters effort put into informal learning.

The TRAILER project proposed the creation of a portfolio for informal learning activities where the learners can create showcases of their informal learning and have them be visible to their institution or company. The platform also provides a decision support system (DSS) for employers to be in touch with the informal learning within their company [29]. TRAILER makes use of cloud services [30] in order to provide a modern and accessible architecture that makes it easy for learners to manage their activity.

Finally, we should also mention the important role of social networks and Virtual Learning Environments (VLEs) in facilitating informal learning. Halliday-Wynes and Beddie [16] argue that the advent of new technologies has led to an evolution of the learning environment and that VLEs, multimedia and social networking tools have given unprecedented access to learning material. But it is not only the access to the material that acts as a catalyst to the volume of informal learning. García-Peñalvo et al. $[31,32]$ argue the importance of knowledge exchange in the Social Web and the influence it has to informal learning, using as an example the MyElvin Social Network for language practice. The interconnection opportunities that exist with the VLEs and the social networks are a very important factor in all kinds of learning. VLEs will most probably connect individuals to their peers since they normally exist to support a relatively homogeneous user base, but more extensive social networks like Facebook, Google Plus and Twitter provide a connection to a hugely heterogeneous network of people with equally disperse opportunities for learning.

\subsection{Competences}

Wrapping up this section, the importance of being able to identify and validate informal learning hinges on the ability to translate all the knowledge gathered through informal means to actual competences. It is these competences that hold the real value for the learner and for all the potential employers. The International Labour Organization (ILO) through the International Standard Classification of Occupation (ISCO), provide a basis for international classification of occupation. Their latest revision ISCO-08 [33, 34], dated December 2007 is used as a reference by a lot of countries looking to improve their alignment with the international standards. However, more than a list of competences, ISCO-08 is a comprehensive list of job titles and specific tasks related to each job.

\section{VALIDATION CHALLENGES}

Due to the nature of non-formal and informal learning, their validation is a complicated issue. The natural tendency is to translate competences acquired through non-formal and informal means to formal ones and try to apply the same validation rules and methods. These methods however tend to be strictly defined and structured and are in many cases unsuitable for evaluating the mostly unstructured activities of informal learning. This relies to the traditional challenge of structuring and formalizing entities that are unstructured and heterogeneous by nature, in order to analyze or process them by means of quantitative or qualitative techniques.

There are a number of identified factors that complicate the validation process of informal learning, especially in international environments where different mechanisms and legislations come into play.

1. Long unwieldy competence lists. The existing competence lists like ISCO-08 need to encompass all possible scenarios. This results in having to shift through huge lists of overly specific competences in order to apply one to an activity without in many cases being certain that it is the most appropriate one.

2. Need for a third-party examiner or observer. Usually, evaluation and validation of a learning process requires the presence of an observer that follows the methods that the learners use. However, in the case of informal learning activities, their unstructured nature and the potential irregularity of the schedule practically rule out efficient observation.

3. Many external stakeholders exerting pressure. As long as there is value perceived in the validation of informal learning, there will be a number of stakeholders interested in participating in the validation process. These stakeholders usually range from national or regional public entities, to private organizations, oftentimes applying different criteria, different requirements, monetary or otherwise and different interests or purposes. These differences complicate the coordination in a national or international level and put in question the validity of the evaluations they offer.

4. Heterogeneity of IL process. By its nature, informal learning is heterogeneous and unstructured. This means that it is possible for two learners to achieve the same level of knowledge on a topic following different activity paths and schedules. Whether the validation process should account for these differences despite the identical end results is a very interesting debate.

5. Internet-based informal learning. The issue is complicated even further when the informal learning activities are Internet based. Informal learning resources may come from a vast selection of sources all over the world. Different backgrounds, cultures, notions and beliefs come into play when analyzing the informal learning process. The capability of a single organization to analyze the validity and value of all these resources is questionable at best.

6. Differences among countries. Even in formal learning contexts, different countries use different metrics and 
procedures for their evaluations. The same is true for informal learning. For this reason it is very complicated to have a coordinated effort for the validation of nonformal and informal learning.

7. Experience. The accuracy of validation and evaluation is subject to the experience of the evaluator. It would be an error to ignore the experience factor when designing the evaluation aspects of the framework.

These factors raise the question of whether applying a validation methodology derived from formal learning experiences is the most efficient and effective way to go about validating non-formal and informal learning.

\section{A SOCIAL APPROACH}

The experience we gathered during the execution of the TRAILER project has led us to consider alternative approaches to the issue of validating non-formal and informal learning. What we propose in this article, is to provide a social framework that will center on peer collaboration and recommendation in order to build a knowledge base not only capable of producing an evaluation of a learner's activity and their progression towards attaining certain competences, but to also provide recommendations based on the activity of their peers.

The idea is that learners will have their private space where they can store all the ILAs they undertake and attach them to a certain competence if it is relevant. If they wish, they can make their activities public to everyone or to a certain group of people (e.g. the people they are related to professionally). These public activities will be ratable, commented upon, followed or adopted by the other members of the community. The traffic and the ratings generated for each activity is a good starting point for its evaluation.

Apart from the active user participation, the platform will implement a recommendation system that will recommend to a learner, activities undertaken by learners with similar informal learning portfolios. So the learner will receive a message with a list of popular activities inserted in the system by other people related to competences or activities from the learner's portfolio. These activities can be both positively rated for the learner to look into, or negatively rated, in order to be avoided. This feature should help further promote informal learning by exposing potentially unknown sources and activities to the learners.

For use within an institution or a company, the platform takes its clues from the one designed for the TRAILER project of the European Lifelong Learning Programme. Learners (in this case employees) choose to make public to the employers and their colleagues certain ILAs. Colleagues and employers get the chance to evaluate these activities. Employers gain a better understanding of the competences existing within the company and are in a position to make better management decisions.

\section{EXPECTED BENEFITS}

We expect to observe a number of beneficial outcomes from this proposed social approach to informal learning.

- Motivation. The ability to follow the activities of other people, see what they are learning and how, is a motivating factor for one's learning activity. It is in the human nature to compare one's self to their peers and try to keep up or to outdo them.

- Evaluation. Learners can see the comments and evaluation their activities are getting. This helps them know how well they are doing, if they are on the right path, if others regard their learning as interesting or useful, etc.

- Collaboration. Two or more learners can use the platform to coordinate their learning activities. They could divide topics among themselves and then interchange experiences in private or they could center on the same topic undertaking the same activities and sharing the same end goal.

- New resources. The recommendation feature of the platform can help learners find resources and activities they did not know about previously. They can also browse the activities of people working on the same competences.

- Transparency. Access to a learner's activities and not just to a declared competence adds an important degree of transparency to their curriculum. The number and quality of informal learning activities related to a competence is a transparent metric for determining a competence's mastery level.

\section{EXISTING RISKS}

In parallel to all the benefits that the social approach may have, there are a number of risks that should be avoided in order to have the platform be a tool that supports and promotes informal learning and not one that strictly controls it.

- Employee control tool. In an institution or company environment there is always the risk of having every progress-registering platform be turned to a tool to control the employees. Especially in the workplace, there is a big risk of having people being discriminated due to their informal learning portfolios, or lack thereof. Strict evaluation platform. The objective of our proposal is a platform that fosters interaction and promotes informal learning. The evaluation mechanisms should be robust, but discreet enough to not overshadow the important aspect of the platform, which is informal learning itself.

- Moderation mechanisms. As any social platform, there are bound to be rivalries, discussions, differences, etc. The evaluation algorithms should be carefully designed so that if a learner evaluates unfairly the activities of a peer, their evaluation will not have a major impact.

- Irrelevant social interactions. Similarly to the above point, great care must be put into deciding what types of interactions will be allowed on the platform. After all, this should be an informal learning platform and not a social interaction tool. Giving too much liberty in how learners can interact with their peers may end up having negative effects to the nature of those interactions.

- Informal learning becomes mandatory. This risk is a more generalized version of the first point of this list. The whole idea of making informal learning visible and valid for a curriculum entails the risk of converting it into something mandatory instead of an added bonus.

- Competence lists. Finally, a risk that we identified during our involvement in the TRAILER project was the unwieldy official competence lists provided international standards organizations. The absence of a cohesive and intuitive list can break the entire platform. If the users have to shift through hundreds of competences in order to identify the most appropriate one for their activity, they will quickly abandon the platform. On the other hand, if the users have absolute 
freedom in defining their own competences, the platform will end up having to juggle an equally huge list of ill-defined competences with many of them referring to the same concept.

All these risks present challenges that will have to be tackled at the design phase of the informal learning evaluation and validation framework.

\section{FRAMEWORK EVALUATION}

In order to evaluate our proposal, we are planning on organizing a couple of rounds of focus tests, where real users from the academia and from the private sector will be able to get their hands on the platform and use it for a short period of time (1-2 weeks). After that time, we will ask them to answer some questions evaluating the platform.

Apart from the answers to the questionnaires, the usage statistics that we will record for the duration of the tests will provide further data for our evaluation.

Again, our experience with the TRAILER project has shown us that these two sources of information can provide a fairly accurate depiction of the learners' perception of the framework, both in terms of interest in the process and the platform's usability.

\section{CONCLUSIONS}

In conclusion, it is made evident that the importance of informal learning is widely accepted and as a consequence, there are many proposals in the literature for its validation. However, these proposals either offer theoretical guidelines for projecting informal learning experiences to formal learning and applying the same rules that are applied to formal learning, or come in the form of tools that offer virtual prizes for learners that register certain activities.

Our proposal comes in the form of an informal learning social collaboration network where learners choose what to expose where and give and receive useful feedback for their activities as well as recommendations for further exploration.

We believe that our proposal achieves more than the rest by using a flexible peer-driven evaluation and validation framework and by offering a recommendation mechanism that helps the learners discover additional activities related to their informal learning curriculae.

\section{ACKNOWLEDGMENTS}

This work has been partially supported by the TRAILER Project (European Lifelong Learning Program).

\section{REFERENCES}

[1] Stehr, Nico. Knowledge societies. Blackwell Publishing Ltd, 1994.

[2] Mansell, Robin, and Uta Wehn, eds. Knowledge societies: Information technology for sustainable development. United Nations Publications, 1998.

[3] University of the Third Age. [Online; accessed 18-February2013].

[4] E. Commission, The Lifelong Learning Programme, 2007 2013. [Online; accessed 18-February-2013].

[5] E. C. for the Development of Vocational Training, European guidelines for validating non-formal and informal learning. Office for Official Publications of the European Communities, 2009.

[6] Y. Punie, D. Zinnbauer, and M. Cabrera, A Review of the Impact of ICT on Learning, JRC 47246 ed., 2008.
[7] Y. Punie, M. Cabrera, M. Bogdanowicz, D. Zinnbauer, and E. Navajas, The Future of ICT and Learning in the Knowledge Society: Report on a Joint DG JRC-DG EAC Workshop Held in Seville. Luxembourg: Office for Official Publications of the European Communities, 2006.

[8] García-Peñalvo, Francisco J., Miguel Á. Conde, Valentina Zangrando, Alicia García-Holgado, Antón M. Seoane, Marc Alier, Nikolas Galanis et al. TRAILER project (Tagging, recognition, acknowledgment of informal learning experiences). A Methodology to make learners' informal learning activities visible to the institutions. Journal of Universal Computer Science 19, no. 11 (2013): 1661-1683.

[9] Peñalvo, Francisco José García, Valentina Zangrando, Alicia García Holgado, M. A. C. Gonzalez, AM Seone Pardo, D. Griffiths, M. A. Forment et al. TRAILER project overview: Tagging, recognition and acknowledgment of informal learning experiences. In Computers in Education (SIIE), 2012 International Symposium on, pp. 1-6. IEEE, 2012.

[10] Viegas, Maria C., Maria A. Marques, Gustavo R. Alves, Valentina Zangandro, Nikolas Galanis, Francis Brouns, José Janssen et al. Using TRAILER tool for Managing Informal Learning in academic and professional contexts: the learners' perspective. In Proceedings of the First International Conference on Technological Ecosystem for Enhancing Multiculturality (TEEM '13). ACM, New York, NY, USA, 529-534.

[11] E. E. H. E. Area, Towards the European higher education area, in Conference of Ministers responsible for Higher Education in 29 European countries, Bologna, Italy, 1999.

[12] CEDEFOP: European Centre for the Development of Vocational Training. [Online; accessed 30-April-2013].

[13] European qualifications framework. [Online; accessed 30April-2013]

[14] M. S. Otero, A. McCoshan, and K. Junge, European inventory on validation of non-formal and informal learning, A Final Report to DG Education \& Culture of the European Commission. ECOTEC Research and Consulting Limited. Birmingham, 2005.

[15] M. Dale, J. Bell, and G. Britain, Informal learning in the workplace. Department for Education and Employment London, 1999.

[16] S. Halliday-Wynes and F. Beddie, Informal learning, 2009.

[17] FREE: Fostering Return to Employment through Entrepreneurship, Innovation and Creativity. [Online; accessed 30-April-2013].

[18] IBAK: Identification, assessment and recognition of informally acquired competences. [Online; accessed 30April-2013].

[19] A. Berlanga, P. Sloep, F. Brouns, M. Bitter-Rijpkema, and R. Koper, Towards a TENCompetence eportfolio. International Journal of Emerging Technologies in Learning (iJET), [S.1.], v. 3, p. pp. 24-28, jul. 2008. ISSN 1863-0383.

[20] J. Schoonenboom, H. Sligte, A. Moghnieh, D. Hern_andezLeo, K. Stefanov, C. Glahn, M. Specht, and R. Lemmers, Supporting life-long competence development using the TENCompetence infrastructure: a first experiment. International Journal of Emerging Technologies in Learning (Special Issue), 3(1), 53-59. July, 2008.

[21] Mahara: Open source e-portfolios. [Online; accessed 30April-2013].

[22] P. Gerbic and M. Maher, Collaborative self-study supporting new technology: The mahara e-portfolio project, Proceedings of ASCILITE Melbourne, pp. 320\{324, 2008. 
[23] M. Brown, B. Anderson, M. Simpson, and G. Suddaby, Showcasing mahara: A new open source e-portfolio, Proceedings of ASCILITE Singapore, pp. 82-84, 2007.

[24] Mozilla: OpenBadges. [Online; accessed 30-April-2013].

[25] Degreed. [Online; accessed 30-April-2013].

[26] J. Fournier, C. Lane, and S. Corbett, The journey to best practices: Results of a two-year study of e-portfolio implementation in beginning composition courses, in World Conference on Educational Multimedia, Hypermedia and Telecommunications, vol. 2007, pp. 2008-2016, 2007.

[27] R. Koper and M. Specht, TENCompetence: Life-long competence development and learning. Innovative Approaches for Learning and Knowledge Sharing Lecture Notes in Computer Science Volume 4227, 2006, pp 621-627.

[28] H. Vogten, R. Koper, H. Martens, and J. Van Bruggen, Using the personal competence manager as a complementary approach to ims learning design authoring, Interactive Learning Environments, vol. 16, no. 1, pp. 83-100, 2008.
[29] García-Peñalvo, F. J., \& Conde, M. Á. (2014). Using informal learning for business decision making and knowledge management. Journal of Business Research, 67(5), 686-691.

[30] García-Peñalvo, F. J., Johnson, M., Ribeiro Alves, G., \& Minovic, M. (2014). Informal learning recognition through a cloud ecosystem. Future Generation Computer Systems, 32, 282-294. F. J. García-Peñalvo, R. Colomo-Palacios, and M. D. Lytras, Informal learning in work environments: training with the social web in the workplace, Behaviour \& Information Technology, vol. 31, no. 8, pp. 753-755, 2012.

[31] F. García-Peñalvo, J. González-González, and M. Murray, Myelvin: a web-based informal learning platform for languages practice, International Journal of Knowledge Society Research (IJKSR), vol. 3, no. 1, pp. 26-39, 2012.

[32] ILO: International Labour Organization - International Standard Classification of Occupations, ISCO-08. [Online; accessed 30-April- 2013].

[33] D. Hunter, ISCO-08 draft definitions, ILO Bureau of Statistics, Geneva, 2009.

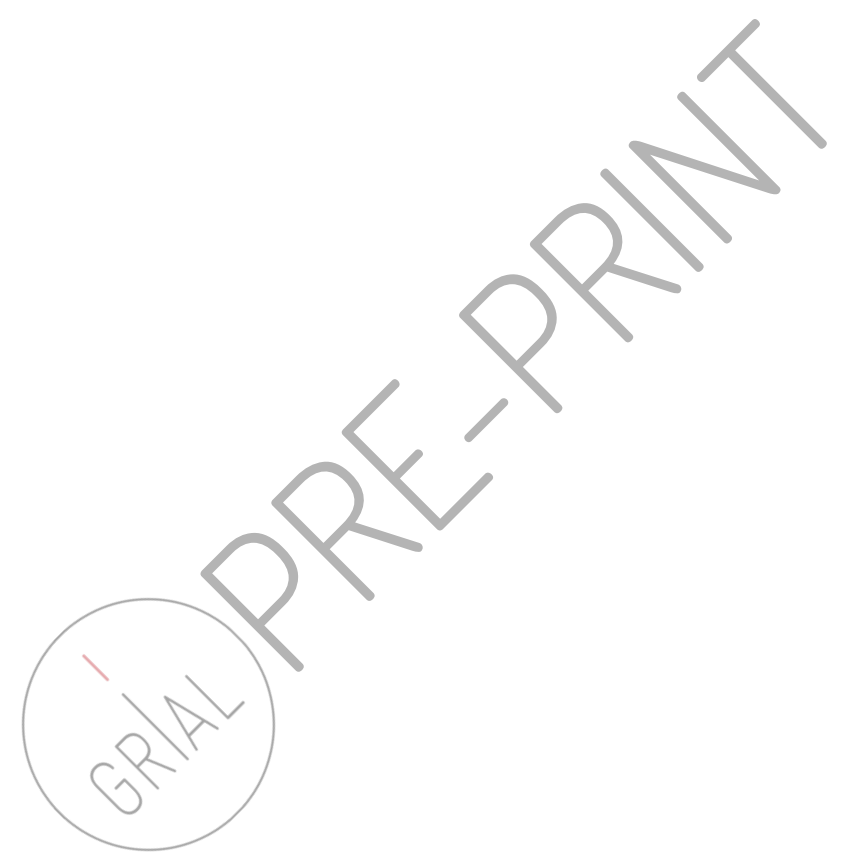

